\title{
Long-term measurements of carbonaceous aerosols in the Eastern Mediterranean: evidence of long-range transport of biomass burning
}

\author{
J. Sciare ${ }^{1}$, K. Oikonomou ${ }^{1}$, O. Favez ${ }^{1}$, E. Liakakou ${ }^{2}$, Z. Markaki ${ }^{2}$, H. Cachier ${ }^{1}$, and N. Mihalopoulos ${ }^{2}$ \\ ${ }^{1}$ Laboratoire des Sciences du Climat et de l'Environnement (LSCE, CNRS-CEA), Gif-sur-Yvette, France \\ ${ }^{2}$ Department of Chemistry, University of Crete, Heraklion, Crete, Greece
}

Received: 16 January 2008 - Published in Atmos. Chem. Phys. Discuss.: 9 April 2008

Revised: 5 August 2008 - Accepted: 20 August 2008 - Published: 17 September 2008

\begin{abstract}
Long-term (5-year) measurements of Elemental Carbon (EC) and Organic Carbon (OC) in bulk aerosols are presented here for the first time in the Mediterranean Basin (Crete Island). A multi-analytical approach (including thermal, optical, and thermo-optical techniques) was applied for these EC and OC measurements. Light absorbing dust aerosols were shown to poorly contribute $(+12 \%$ on a yearly average) to light absorption coefficient $\left(b_{\mathrm{abs}}\right)$ measurements performed by an optical method (aethalometer). Long-range transport of agricultural waste burning from European countries surrounding the Black Sea was shown for each year during two periods (March-April and July-September). The contribution of biomass burning to the concentrations of EC and OC was shown to be rather small (20 and 14\%, respectively, on a yearly basis), although this contribution could be much higher on a monthly basis and showed important seasonal and interannual variability. By removing the biomass burning influence, our data revealed an important seasonal variation of $\mathrm{OC}$, with an increase by almost a factor of two for the spring months of May and June, whereas BC was found to be quite stable throughout the year. Preliminary measurements of Water Soluble Organic Carbon (WSOC) have shown that the monthly mean WSOC/OC ratio remains stable throughout the year $(0.45 \pm 0.12)$, suggesting that the partitioning between water soluble and water insoluble organic matter is not significantly affected by biomass burning and secondary organic aerosol (SOA) formation. A chemical mass closure performed in the fine mode (Aerodynamic Diameter, A.D. $<1.5 \mu \mathrm{m}$ ) showed that the mass contribution of organic matter (POM) was found to be essentially invariable during the year (monthly average of $26 \pm 5 \%$ ).
\end{abstract}

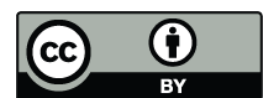

Correspondence to: N. Mihalopoulos (mihalo@chemistry.uoc.gr)

\section{Introduction}

Recent studies demonstrate the significant role of elemental carbon (EC) aerosols in the Eastern Mediterranean (Lelieveld et al., 2002; Sciare et al., 2003b) with negative surface radiative forcing and large positive atmospheric forcing values nearly identical to the highly absorbing south Asian haze observed over the Arabian Sea (Markowicz et al., 2002). The contribution of these light absorbing particles is particularly important during the summer period when most of air masses over the Eastern Mediterranean originate from the Balkans, Turkey and Central/Eastern Europe (Vrekoussis et al., 2005; Bryant et al., 2006). During this period, continental (anthropogenic) aerosols, mainly composed of sulfate and carbonaceous material, contribute for almost $2 / 3$ of the Aerosol Optical Depth (AOD) over the Greek-Turkish coastal region (Barnaba and Gobbi, 2004). Extensive forest fires from southern Europe and desert dust plumes from North Africa may also be significantly contributing to largescale aerosol emissions in the Mediterranean environment. Since aerosol types emitted from the above mentioned phenomena significantly absorb solar radiation and contain trace elements such as phosphorus and iron, they can influence the atmospheric physics and the marine biogeochemistry of the Mediterranean (Guieu et al., 2005; Meloni et al., 2006; Bonnet and Guieu, 2006).

Most of studies clearly indicate the major role of carbonaceous material on aerosol optical properties in the Mediterranean region but still few are based on field observations which are particularly scarce and time limited (Sciare et al., 2003a and 2005). The few of them performed in the Eastern part of Mediterranean have shown that a proper analytical determination of their concentrations remains a difficult task primarily due to the complexity of the aerosol mixtures (Sciare et al., 2003b; Bardouki et al., 2003).

Published by Copernicus Publications on behalf of the European Geosciences Union. 

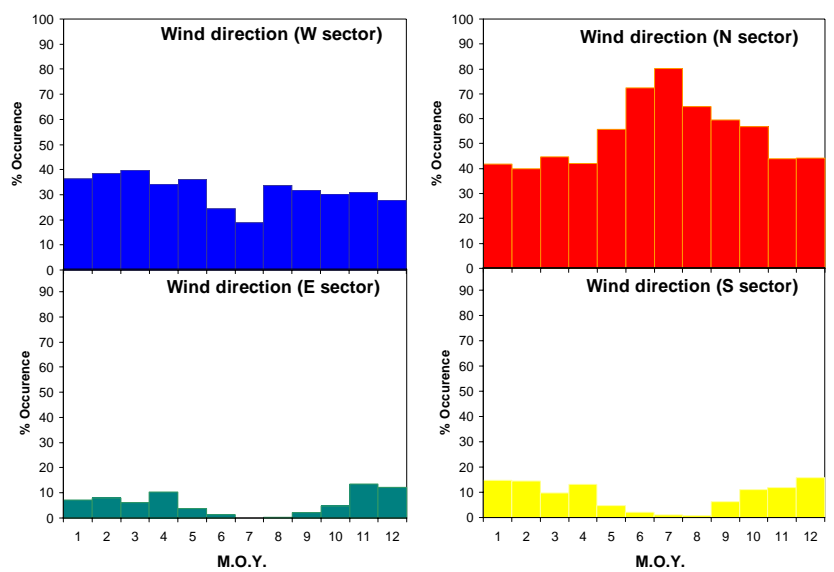

Fig. 1. Yearly-based wind direction occurrences for the 4 sectors (North, West, East, and South) at Finokalia station in Crete Isl. M.O.Y stands for Month Of the Year.

Soot is determined either optically or chemically. The optical method relies on light absorption; the corresponding operational definition for soot is black carbon (BC). The chemical (thermal and thermo-optical) measurements measure the mass concentration of total carbon, in which the fraction that is refractory and does not volatilize below $400^{\circ}$ in air is defined as elemental carbon (EC) (Birch and Cary, 1996). Distinction is done in the following between $\mathrm{EC}$ and $\mathrm{BC}$ since they refer to somewhat different fractions of light absorbing carbon.

Among the major outcomes from carbonaceous aerosol studies in the Mediterranean, important discrepancies were observed in the determination of summertime EC concentrations from the use of different analytical protocols. EC concentrations derived from the IMPROVE thermo-optical protocol (Chow et al., 1993) and light absorption measurements (PSAP, Radiance Research) showed a very good correlation with non-sea-salt potassium (nss- $\mathrm{K}^{+}$), considered to be a tracer of biomass burning. On the other hand, EC concentrations derived from a 2-step thermal method (Cachier et al., 1989) and performed on the same filter samples showed to better correlate with non-sea-salt sulfate $\left(\mathrm{nss}-\mathrm{SO}_{4}^{2-}\right)$ which is considered as a tracer for fossil fuel combustion. The proper analysis of carbonaceous aerosols over the Mediterranean is even more complicated by the presence of important dust concentrations deposited on quartz filter matrix that interfere in many ways with light absorption measurements as well as on thermo-optical measurements of EC and OC. The above drawbacks originate either from the presence of absorbing ferric iron oxides (hematite and goethite) contained in the dust particles and/or release of oxygen contained in the metallic oxides that compose dust aerosols during the He step of the thermo-optical method. All these results indicate that the proper determination of the different carbonaceous fractions (EC and OC) in the dusty environment of the Mediterranean remains a challenge.
Long-term measurements of carbonaceous aerosols are presented here for the first time over the Mediterranean Sea (Crete Isl.). Their concentrations and seasonal variations are discussed from the use of different analytical methods. Their relative mass contribution to the fine aerosol mass (A.D. $<$ $1.5 \mu \mathrm{m}$ ) is evaluated from a chemical mass closure (CMC) study. The multi-year record of EC and OC obtained here is used to investigate the role of long-range transport of biomass burning aerosols in the region as well as the role of secondary organic aerosol formation.

\section{Instrumentation}

\subsection{Sampling site and climatology}

The atmospheric station of Finokalia (Crete Isl., Greece) is located in the marine boundary layer $\left(35^{\circ} 20^{\prime} \mathrm{N}, 25^{\circ} 40^{\prime} \mathrm{E}\right.$; $200 \mathrm{~m}$ above sea level), facing the Aegean Sea and located at approximately $500 \mathrm{~m}$ from the shore. A detailed description of the climatology of this site can be found in Kouvarakis et al. (2000) and Gerasopoulos et al. (2006).

Seasonal variations of wind sectors at Finokalia station are reported in Fig. 1. They are calculated from backtrajectory analysis every $12 \mathrm{~h}$, with the Hysplit Dispersion Model (Hybrid Single - Particle Lagrangian Integrated Trajectory; Draxler and Hess, 1998) using the location of air parcels $24 \mathrm{~h}$ before arrival at Finokalia Station. Seasonal variations of wind sectors are computed for the duration of the filter sampling reported here (from September 2001 to December 2006). Each wind sector covers a $90^{\circ}$ sector centred on each direction (North, East, South, and West). On a yearly basis, more than half of the air masses arriving in Crete originate from the North sector, which covers Central and Eastern Europe as well as part of western Turkey. This northern contribution reaches almost $75 \%$ during the summer months, when the photochemistry is at its highest. This pattern clearly shows that the Eastern Mediterranean Basin is strongly influenced by long-range transport of continental air masses and makes Finokalia station a particularly well-suited receptor site to characterize the poorly documented emissions from Central/Eastern Europe as well as their ageing.

\subsection{Aerosol sampling}

The long-term aerosol chemical measurements presented here are based on the filter sampling devices that have been used during the MINOS campaign in August 2001 (see Sciare et al., 2003b and 2005 for more details). Briefly, total suspended particulate (TSP) samples are collected on 47-mm diameter quartz fiber filters (QMA, Whatman) at a flowrate of approximately $2.8 \mathrm{~m}^{3} / \mathrm{h}$ for carbon analysis (BC, OC, WSOC). Co-located Stacked Filter Units (SFUs) using polycarbonate filters are used in parallel for gravimetric measurements and ion analysis. SFU filters consist of an $8 \mu \mathrm{m}$ pore size $47-\mathrm{mm}$ diameter Nuclepore filter mounted in front 
of a $0.4 \mu \mathrm{m}$ pore size $47-\mathrm{mm}$ diameter Nuclepore filter. The $50 \%$ cut point diameter $\left(\mathrm{D}_{50}\right)$ of the $8 \mu \mathrm{m}$ Nuclepore filter was estimated to be of the order of $1.5 \pm 0.5 \mu \mathrm{m}$ based on the adopted flowrate of $1.5 \mathrm{~m}^{3} / \mathrm{h}$. In this paper, the aerosol coarse fraction will refer to the particles collected on the $8 \mu \mathrm{m}$ pore size filters and thus having an A.D. larger than $1.5 \mu \mathrm{m}$. Conversely, the fine fraction refers to particles collected on the $0.4 \mu \mathrm{m}$ pore size filters and corresponds to particles with an A.D. below $1.5 \mu \mathrm{m}$.

Typical filter sampling time is of the order of 1 week (7.7 \pm 2.9 days). It covers a 3.5-year period (09/200104/2004) for SFU filters and a 5-year period for QMA filters (09/2001-11/2006). SFU and QMA filters have been sampled in parallel during the period (09/2001-04/2004). A sequential sampling of $15 \mathrm{~min}$ every $1 \mathrm{~h}$ was applied for both SFU and QMA filters, which corresponds to less than 2 days of continuous sampling. This was performed to minimize filter clogging that may appear for long time sampling of SFUs and that may induce a rapid decrease of flowrate. Flowrate of SFU filters was checked carefully at the beginning and the end of each sampling for that purpose.

\section{Analysis}

\subsection{Thermal and thermo-optical carbon analyses}

One thermal and two thermo-optical techniques have been used to determine the EC and OC contents on the quartz filters. They are presented and discussed in details by Sciare et al. (2003b) and are briefly reported here. To avoid interference by carbonates, all samples were initially treated with $\mathrm{HCl}$ fumes using the protocol designed by Cachier et al. (1989). Artifacts due to the absorption of gas-phase organic compounds on the sample substrate were minimized by heating filters for 20 minutes at $60^{\circ} \mathrm{C}$ prior to the analyses. The EC and OC concentrations for the quartz filters were measured with a thermo-optical light transmission technique (Sunset Carbon Analyzer Instrument; Birch and Cary, 1996). Two temperature programs were implemented in the Sunset instrument and correspond to the temperature programs used in the IMPROVE and NIOSH protocols, respectively (Chow et al., 1993; NIOSH, 1996 and 1998). EC measurements from these two temperature programs are reported as $\mathrm{EC}(\mathrm{NIOSH})$ and EC(IMPROVE) in the following. Finally, EC was also determined using a 2-step thermal method developed by Cachier et al. (1989) and is reported later as EC(2-STEP). Filters taken regularly in the field (and used as blanks) did not show a detectable amount of EC but showed OC concentrations of $0.8 \mu \mathrm{gC} / \mathrm{cm}^{2}$, on average. Blank corrections were then performed only for $\mathrm{OC}$ and represent on average less than $5 \%$ of the OC measurements performed during the study. Uncertainties in the BC and OC measurements given by the manufacturer (Sunset Lab, OR) are estimated to be of the order of $5 \% \pm 0.2 \mu \mathrm{gC} / \mathrm{cm}^{2}$.

\subsection{Light absorption measurements}

A circle punch of $18 \mathrm{~mm}$ diameter was taken on each QMA filter to perform a non-destructive optical measurement of the light absorption using a modified aethalometer model AE9 manufactured by Magee Scientific (Hansen et al., 1982). This Aethalometer is working with an incandescent light with a broad spectral distribution. The spectral response of a similar instrument (AE-10) is given by Weingartner et al. (2003). The aerosol absorption coefficient $\left(b_{A T N}\right)$ determined in this way may differ significantly from the true aerosol absorption coefficient $\left(b_{a b s}\right)$ of airborne particles (Weingartner et al., 2003). Therefore, calibration factors $\mathrm{C}$ and R(ATN) are introduced, which can convert aethalometer attenuation measurements to "real" absorption coefficients following the equation:

$b_{\mathrm{abs}}=\sigma_{\mathrm{abs}} \times b_{\mathrm{ATN}} /\left(\sigma_{\mathrm{ATN}} \times \mathrm{R}(\mathrm{ATN})\right)$

where $\sigma_{\mathrm{abs}}$ and $\sigma_{\mathrm{ATN}}\left(\right.$ equal to $\sigma_{\mathrm{abs}} \times \mathrm{C}$ ) are the mass specific absorption and attenuation cross-section (in units of $\mathrm{m}^{2} \mathrm{~g}^{-1}$ ), respectively. Following the recommendation of the constructor a $\sigma_{\mathrm{ATN}}$ value of $19 \mathrm{~m}^{2} \mathrm{~g}^{-1}$ was used in this work. Weingartner et al. (2003) have proposed an R-value close to 1 for aged atmospheric aerosols at remote site, as the high amount of scattering aerosol material in the fiber matrix compensating the shadowing effect related to $\mathrm{R}$. The same authors have also proposed a $\mathrm{C}$ value of 1.9 corresponding to aged atmospheric particles. Following these results, our absorption coefficients were calculated with $\mathrm{R}$ and $\mathrm{C}$ values of 1 and 1.9, respectively. Aethalometer $\mathrm{BC}$ measurements are reported in the following as BC(AETHALO).

\subsection{Water Soluble Organic Carbon analysis}

Water Soluble Organic Carbon analyses were performed on 49 samples covering the period (10/2005-07/2006). Three quarter of the quartz filter (previously used for EC and OC determinations) was dedicated for this analysis by using a total organic carbon analyser (TOC, Model Sievers 900, Ionics Ltd, USA). Filter extraction was conducted through overnight soft shaking of the filter portion placed in borosilicate Erlenmeyer flasks with $25 \mathrm{~mL}$ of ultra pure water (obtained by ELGA maxima HPLC). Prior to analysis, the extract solution was filtered through Teflon (PTFE) filters $(0.2 \mu \mathrm{m}$ pore size diameter), to remove suspended particles. The measurement uncertainty given by the manufacturer is of the order of $7 \%$. Blank values for the water (used for the filter extraction) and blank values for the filters were found to be on average $50 \pm 20 \mathrm{ppb}$ and $250 \pm 50 \mathrm{ppb}$, respectively. The overall blank value of the order of $300 \pm 70 \mathrm{ppb}$ corresponds on average to $16.4 \pm 8.5 \%$ of the mean WSOC value determined for the 49 sampled QMA filters. Analyses were duplicated for each QMA sample and good reproducibility (deviation of the order of $1 \%$ ) was obtained. Water Insoluble Organic Carbon (WIOC) mass concentrations were calculated 
Table 1. Monthly mean concentrations of the major aerosol chemical components, particulate matter (PM), and reconstructed PM from the chemical mass closure $\left(\mathrm{PM}_{\mathrm{CMC}}\right)$ in the fine mode (A.D. $\left.<1.5 \mu \mathrm{m}\right)$. Standard deviations $(1 \sigma)$ are reported in brackets. Data collected for the 3.5-year period (09/2001-04/2004).

\begin{tabular}{|c|c|c|c|c|c|c|c|c|c|}
\hline Month of the Year & $\begin{array}{c}\text { EC (IMPROVE) } \\
\mu \mathrm{gC} / \mathrm{m}^{3}\end{array}$ & $\begin{array}{c}\text { OC (IMPROVE) } \\
\mu \mathrm{gC} / \mathrm{m}^{3}\end{array}$ & $\begin{array}{c}\text { nss- } \mathrm{SO}_{4} \text { Fine } \\
\mu \mathrm{g} / \mathrm{m}^{3}\end{array}$ & $\begin{array}{c}\mathrm{NH}_{4} \text { Fine } \\
\mu \mathrm{g} / \mathrm{m}^{3}\end{array}$ & $\begin{array}{c}\mathrm{NO}_{3} \text { Fine } \\
\mu \mathrm{g} / \mathrm{m}^{3}\end{array}$ & $\begin{array}{c}\text { sea salt Fine } \\
\mu \mathrm{g} / \mathrm{m}^{3}\end{array}$ & $\begin{array}{l}\text { dust Fine } \\
\mu \mathrm{g} / \mathrm{m}^{3}\end{array}$ & $\begin{array}{c}\mathrm{PM}_{\mathrm{CMC}} \text { Fine } \\
\mu \mathrm{g} / \mathrm{m}^{3}\end{array}$ & $\begin{array}{l}\text { PM Fine } \\
\mu \mathrm{g} / \mathrm{m}^{3}\end{array}$ \\
\hline January & $0.18(0.07)$ & $1.13(0.07)$ & $1.99(1.14)$ & $0.39(0.40)$ & $0.11(0.13)$ & $2.07(2.56)$ & $1.44(1.84)$ & $9.66(5.30)$ & $10.45(4.98)$ \\
\hline February & $0.30(0.12)$ & $1.38(0.31)$ & $3.34(1.00)$ & $0.94(0.33)$ & $0.03(0.00)$ & $0.40(0.15)$ & $0.37(0.38)$ & $8.68(2.50)$ & $7.77(4.89)$ \\
\hline March & $0.37(0.13)$ & $1.81(0.25)$ & $3.25(0.22)$ & $0.86(0.10)$ & $0.04(0.01)$ & $0.36(0.09)$ & $1.57(0.23)$ & $9.18(0.03)$ & $9.42(0.87)$ \\
\hline April & $0.37(0.11)$ & $1.78(0.48)$ & $3.97(0.17)$ & $1.11(0.05)$ & $0.05(0.04)$ & $0.34(0.04)$ & $1.22(0.92)$ & $9.71(1.81)$ & $9.09(0.40)$ \\
\hline May & $0.27(0.04)$ & $1.68(0.65)$ & $3.26(0.80)$ & $0.98(0.25)$ & $0.03(0.01)$ & $0.26(0.01)$ & $0.75(0.39)$ & $0.75(2.31)$ & $6.47(2.98)$ \\
\hline June & $0.26(0.04)$ & $2.04(0.48)$ & $4.85(0.27)$ & $1.34(0.08)$ & $0.06(0.04)$ & $0.29(0.06)$ & $1.17(0.03)$ & $8.93(0.20)$ & $9.09(1.39)$ \\
\hline July & $0.36(0.17)$ & $2.18(0.65)$ & $4.61(1.05)$ & $1.18(0.29)$ & $0.04(0.01)$ & $0.36(0.01)$ & $0.59(0.06)$ & $10.88(0.13)$ & $9.57(0.39)$ \\
\hline August & $0.39(0.02)$ & $2.16(0.91)$ & $5.33(1.43)$ & $1.27(0.30)$ & $0.06(0.03)$ & $0.38(0.10)$ & $1.33(0.29)$ & $10.35(1.80)$ & $9.46(1.63)$ \\
\hline September & $0.40(0.09)$ & $2.16(0.39)$ & $2.94(0.64)$ & $0.72(0.09)$ & $0.04(0.03)$ & $0.23(0.12)$ & $1.12(1.03)$ & $11.40(2.28)$ & $7.65(2.89)$ \\
\hline October & $0.35(0.11)$ & $1.67(0.33)$ & $3.65(1.98)$ & $0.97(0.58)$ & $0.04(0.02)$ & $0.27(0.08)$ & $0.59(0.50)$ & $7.29(2.92)$ & $8.91(2.48)$ \\
\hline November & $0.23(0.03)$ & $1.51(0.65)$ & $2.27(0.03)$ & $0.51(0.02)$ & $0.08(0.03)$ & $0.44(0.02)$ & $1.60(0.02)$ & $8.29(0.46)$ & $7.41(0.31)$ \\
\hline December & $0.25(0.11)$ & $1.35(0.50)$ & $1.00(1.13)$ & $0.18(0.21)$ & $0.08(0.06)$ & $1.43(1.28)$ & $1.08(0.92)$ & $6.97(1.19)$ & $6.40(2.93)$ \\
\hline Yearly average & $0.31(0.07)$ & $1.74(0.35)$ & $3.37(1.24)$ & $0.87(0.36)$ & $0.05(0.02)$ & $0.57(0.57)$ & $1.07(0.41)$ & $8.88(1.75)$ & $8.47(1.30)$ \\
\hline
\end{tabular}

as the difference between OC and WSOC mass concentrations.

\subsection{Ion Chromatography analysis}

Ion chromatography analysis of SFU filters was performed at LSCE in order to determine selected anions (Acetate, Propionate, Formate, Methanesulfonate, Glutarate, Succinate, Oxalate, Chloride, Sulfate, nitrate, and Phosphate) and cations (Sodium, Ammonium, Potassium, Magnesium, Calcium) using the protocol reported in detail by Sciare et al. (2007). The overall measurement uncertainty in the determination of ionic species is of the order of $5 \%$ and takes into account the filter blank variability, the filter extraction efficiency, and the calibration precision. The contribution of sea salt to the levels of $\mathrm{SO}_{4}^{2-}, \mathrm{Ca}^{2+}$ and $\mathrm{K}^{+}$was estimated using their corresponding seawater mass ratios to $\mathrm{Na}^{+}$of $0.252,0.038$, and 0.037 , respectively. Non-sea-salt potassium (nss-K) concentrations reported later are those calculated in the fine aerosol mode (A.D. $<1.5 \mu \mathrm{m}$ ) and represent on average more than $75 \%$ of nss-K bulk concentrations.

\subsection{Gravimetric analysis}

The Nuclepore filters from the SFUs were weighed at LSCE after $24 \mathrm{~h}$ equilibration at room temperature and RH below $10 \%$ to minimize the bias due to water uptake onto hydrophilic aerosol species deposited on the filters. Measurements have been performed using a Mettler Microbalance UMT3 with $1 \mu \mathrm{g}$ sensitivity. The uncertainty in the gravimetric measurement is typically of the order of $10 \mu \mathrm{g}$, which represents here an average measurement uncertainty below $2 \%$ for particulate mass (PM) measurements in the fine and coarse size fractions.

\subsection{Chemical Mass Closure (CMC)}

The weekly SFU filter sampling covering a 3.5-year period (09/2001-04/2004), and co-located QMA filters sampled in parallel are used in the following to perform a CMC in the fine aerosol mode. All the hypotheses using here to perform the CMC were taken from the mass closure study reported in Sciare et al. (2005) for the MINOS campaign and are briefly reported here. Non-sea-salt-Calcium is used as a dust tracer and its concentrations, determined by IC, are divided by 0.09 to obtain mass concentration of dust. Sea salt sulfate (ss$\mathrm{SO}_{4}$ ), potassium (ss-K), and calcium (ss-Ca) were calculated using $\mathrm{Na}$ as reference and the $\mathrm{SO}_{4} / \mathrm{Na}, \mathrm{K} / \mathrm{Na}$, and $\mathrm{Ca} / \mathrm{Na}$ ratios in bulk seawater. Finally sea salt was calculated using the following equation:

$[$ seasalt $]=1.326[\mathrm{Na}]+[\mathrm{Cl}]+[\mathrm{Mg}]$

Mass Contribution of carbonaceous aerosols is derived using EC(IMPROVE) and OC(IMPROVE). The mass contribution of particulate organic matter (POM) is estimated assuming an OC-to-POM conversion factor of 1.8. Concentrations of EC and OC in the fine mode are estimated from bulk concentrations assuming that $70 \%$ and $90 \%$ of bulk OC and EC concentrations, respectively, are present in the fine mode. Based on these hypotheses, reconstruction of the particulate mass $(\mathrm{PM})$ in the fine from $\mathrm{CMC}\left(\mathrm{PM}_{\mathrm{CMC}}\right)$ is then calculated as:

$$
\begin{aligned}
& \mathrm{PM}_{\mathrm{CMC}}=[\mathrm{EC}]+[\mathrm{POM}] \\
& +\left[\mathrm{NH}_{4}^{+}\right]+\left[\mathrm{nss}-\mathrm{SO}_{4}^{2-}\right]+\left[\mathrm{NO}_{3}^{-}\right]+[\text {seasalt }]+[\text { dust }]
\end{aligned}
$$




\section{Results and discussion}

\subsection{Chemical Mass Closure of fine aerosols}

Monthly mean concentrations of the major aerosol species, $\mathrm{PM}$ and $\mathrm{PM}_{\mathrm{CMC}}$ are given for the fine mode in Table 1 and are calculated for the 3.5-year period, when SFU filter measurements are available (09/2001-04/2004). PM CMC $_{\text {data }}$ reported in this Table 1 stand for monthly mean of $\mathrm{PM}_{\mathrm{CMC}}$ calculated from each individual filter sample.

On a yearly average, sulfate aerosols $\left(\mathrm{NH}_{4}^{+}+\mathrm{nss}-\mathrm{SO}_{4}^{2-}\right)$ are, by far, the major component in the fine mode, contributing to $50 \%$ of the PM mass; the carbonaceous aerosols $(\mathrm{EC}+\mathrm{POM})$ and primary particles (sea salt + dust) contributing only to $29 \%$ and $19 \%$ of PM, respectively, for the same period. The mass contribution of organic matter (POM) to the total fine mass is found to be quite stable during the year (monthly average of $26 \pm 5 \%$ ) despite the fact that the highest EC and OC concentrations are found for the summer months. The contribution of nitrate aerosols is not significant $\left(0.05 \mu \mathrm{g} / \mathrm{m}^{3}\right.$ on a yearly average $)$ and can reasonably be explained by the fact that the warmer temperatures of the Eastern Mediterranean are likely to prevent most of the time condensation of semi-volatile ammonium nitrate. All these results, and in particular the major role of sulfate aerosols, are consistent with those reported at the same location by Bardouki et al. (2003) which are based on the chemical composition of size-resolved atmospheric aerosols during summer and winter. A mean standard deviation of $0.7 \pm 0.5 \mu \mathrm{g} / \mathrm{m}^{3}$ $(8.4 \pm 6.0 \%)$ is calculated between monthly mean PM and $\mathrm{PM}_{\mathrm{CMC}}$ (Table 1), demonstrating the consistencies of the hypotheses used in the CMC of fine aerosols (Sect. 3.6). The yearly PM average of $8.5 \mu \mathrm{g} / \mathrm{m}^{3}$ obtained for the fine mode for the period (09/2001-04/2004) is close to the PM average value of $10.1 \mu \mathrm{g} / \mathrm{m}^{3}$ reported at the same location for a 2-year period (07/2004-07/2006) for submicron aerosols (A.D. $<1 \mu \mathrm{m}$ ) obtained from aerosol samples collected using a Small-Deposit-area low-pressure-Impactor (Gerasopoulos et al., 2007).

Based on the PM contribution of sulfate and organic aerosols in the fine mode (of 50 and $26 \%$, respectively, on a yearly average) and assuming that light scattering properties of sulfate aerosols will be enhanced by water uptake onto particles in the humid environment of the Mediterranean, it may be assumed that sulfate aerosols (more than organics) will play a major role on the direct radiative forcing by aerosols in the Eastern Mediterranean. This statement is consistent with the light scattering coefficient contribution of $2 / 3$ calculated by Sciare et al. (2005) for sulfate aerosols during the MINOS campaign. It is also consistent with the results reported by Vrekoussis et al. (2005) who have noticed significant correlations between nss- $\mathrm{SO}_{4}$ and light scattering coefficient for the remote marine atmosphere of the Eastern Mediterranean. Although the light scattering contribution of organics is expected to be rather small (relatively to sulfates) over the E.

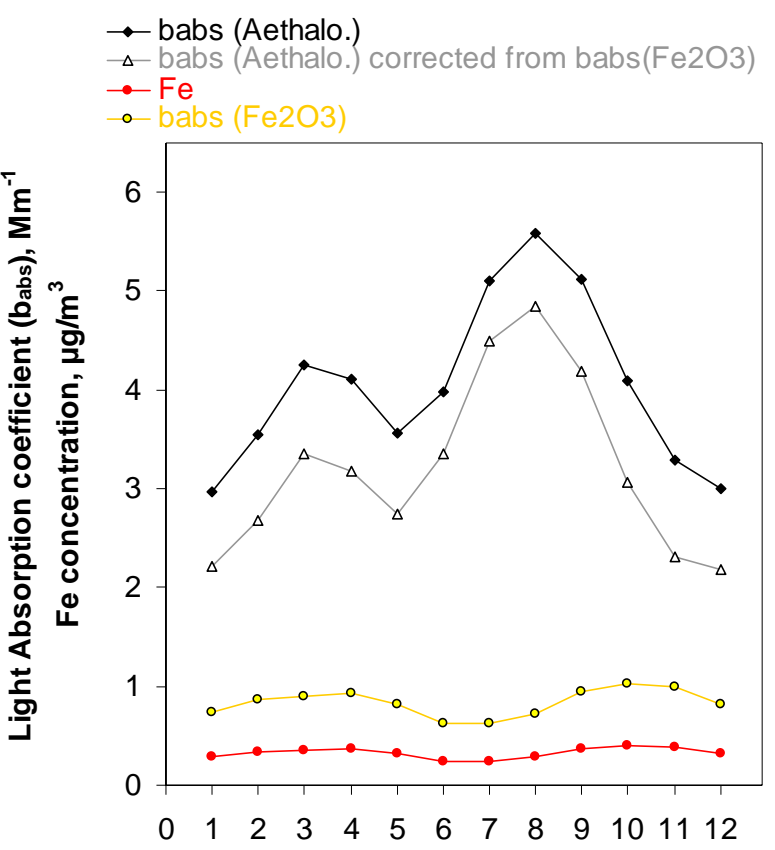

M.O.Y.

Fig. 2. Seasonal variations of iron concentration in dust aerosols and light absorption measurements obtained from aethalometer $\left(b_{\mathrm{abs}}(\mathrm{AETHALO})\right)$ corrected and uncorrected from the light absorption due to dust aerosols $\left(b_{\mathrm{abs}}\left(\mathrm{Fe}_{2} \mathrm{O}_{3}\right)\right)$. Grey bands refer to the two biomass burning periods (March/April) and (July-September).

Mediterranean, the role of black carbon on aerosol absorption properties is expected to be quite significant. For this reason, the emphasis is given on EC concentration levels, variability and origin, in the next section.

\subsection{Light absorption coefficient $b_{a b s}$}

The high loadings of Saharan dust aerosols over the Mediterranean are expected to play a significant role on the light absorbing properties of aerosols due to the presence of hematite $\left(\mathrm{Fe}_{2} \mathrm{O}_{3}\right)$ in dust particles. Dust aerosol absorption may be then deduced from the light absorption coefficient $\left(b_{a b s}\right)$ measurements performed by the aethalometer. The correction referring to the absorption of dust aerosols can be written as:

$b_{\text {abs }}\left(\mathrm{Fe}_{2} \mathrm{O}_{3}\right)=\alpha_{\mathrm{Fe}_{2} \mathrm{O}_{3}} \times\left[\mathrm{Fe}_{2} \mathrm{O}_{3}\right]$

where $\left[\mathrm{Fe}_{2} \mathrm{O}_{3}\right]$ refers to the atmospheric concentration of hematite in dust aerosols (in $\mu \mathrm{g} / \mathrm{m}^{3}$ ) and $\alpha_{\mathrm{Fe}_{2} \mathrm{O}_{3}}$ to the light absorption cross-section of hematite. Assuming that the major fraction of iron is found in dust aerosols as hematite, equation (4) can be re-written using [Fe] and $\alpha_{\mathrm{Fe}}$ (instead of $\left[\mathrm{Fe}_{2} \mathrm{O}_{3}\right]$ and $\alpha_{\mathrm{Fe}_{2} \mathrm{O}_{3}}$ ). Concentrations of $\mathrm{Fe}$ in our samples were derived from an $[\mathrm{Fe}] /\left[\mathrm{nss}-\mathrm{Ca}^{2+}\right]$ mass ratio of 0.52 found in dust aerosols collected in Crete (Sciare et 
Table 2. Intercomparison of soot carbon measurements from 4 different methods: Two thermo-optical techniques (IMPROVE, NIOSH), one optical (AETHALO), and one thermal (2-STEP). $(\sigma)$ stands for the precision as defined by Lewtas et al. (2001)

\begin{tabular}{|c|c|c|c|c|c|c|c|c|c|}
\hline Y vs $\mathrm{X}$ & $\mathrm{N}$ & Period & Slope & Intercept $\mu \mathrm{gC} / \mathrm{m}^{3}$ & $\mathrm{r}^{2}$ & X Average $\mu \mathrm{gC} / \mathrm{m}^{3}$ & $(\mathrm{X}-\mathrm{Y})$ bias $\mu \mathrm{gC} / \mathrm{m}^{3}$ & $\sigma \mu \mathrm{gC} / \mathrm{m}^{3}$ & $\sigma \%$ \\
\hline $\begin{array}{l}\text { EC(NIOSH) vs } \\
\text { EC(IMPROVE) }\end{array}$ & 151 & $\begin{array}{c}(09 / 2001-04 / 2004) \& \\
(10 / 2005-12 / 2006)\end{array}$ & $\begin{array}{l}0.80 \pm 0.04 \\
0.86 \pm 0.02\end{array}$ & $\begin{array}{c}0.03 \pm 0.02 \\
0\end{array}$ & $\begin{array}{l}0.68 \\
0.67\end{array}$ & 0.33 & 0.06 & 0.10 & 32.4 \\
\hline $\begin{array}{l}\text { BC(AETHALO) vs } \\
\text { EC(IMPROVE) }\end{array}$ & 257 & $(09 / 2001-10 / 2005)$ & $\begin{array}{l}1.16 \pm 0.04 \\
1.29 \pm 0.02\end{array}$ & $\begin{array}{c}0.06 \pm 0.02 \\
0\end{array}$ & $\begin{array}{l}0.76 \\
0.75\end{array}$ & 0.34 & 0.10 & 0.07 & 18.27 \\
\hline $\begin{array}{l}\text { EC(2-STEP) vs } \\
\text { EC(IMPROVE) }\end{array}$ & 61 & $(09 / 2001-03 / 2003)$ & $\begin{array}{l}1.54 \pm 0.22 \\
1.56 \pm 0.09\end{array}$ & $\begin{array}{c}0.01 \pm 0.08 \\
0\end{array}$ & $\begin{array}{l}0.46 \\
0.46\end{array}$ & 0.32 & 0.16 & 0.22 & 53.0 \\
\hline $\begin{array}{l}\text { BC(AETHALO) vs } \\
\text { EC(NIOSH) }\end{array}$ & 86 & $(09 / 2001-04 / 2004)$ & $\begin{array}{l}1.09 \pm 0.09 \\
1.54 \pm 0.05\end{array}$ & $\begin{array}{c}0.13 \pm 0.02 \\
0\end{array}$ & $\begin{array}{l}0.65 \\
0.52\end{array}$ & 0.24 & 0.11 & 0.13 & 40.5 \\
\hline
\end{tabular}

al., 2005 and Mihalopoulos et al., unpublished results) and $\left[\mathrm{nss}-\mathrm{Ca}^{2+}\right]$ obtained from the IC analysis of SFU filters. A light absorption cross-section of $2.55 \mathrm{~m}^{2} \mathrm{~g}^{-1}$ (at $550 \mathrm{~nm}$ ) was obtained from the elemental iron calibration constant $\mathrm{K}_{\mathrm{Fe}}$ of $0.234 \pm 0.022 \mu \mathrm{m}^{4} \mathrm{~m}^{2} \mathrm{~g}^{-1}$ determined by Fialho et al. (2005) for Saharan dust aerosols. Seasonal variations of $\mathrm{b}_{\mathrm{abs}}\left(\mathrm{Fe}_{2} \mathrm{O}_{3}\right), \mathrm{b}_{\mathrm{abs}}(\mathrm{AETHALO})$ and $[\mathrm{Fe}]$ were derived from the 3.5-year period when SFU filter measurements were available and are given in Fig. 2. The difference between $\mathrm{b}_{\mathrm{abs}}(\mathrm{AETHALO})$ and $\mathrm{b}_{\mathrm{abs}}\left(\mathrm{Fe}_{2} \mathrm{O}_{3}\right)$ is also shown in this figure and stands for the corrected $b_{a b s}$ (AETHALO). The light absorption coefficient due to dust aerosols shows a weak seasonal variation with a minimum of $0.5 \mathrm{Mm}^{-1}$ during the summer months and two maxima of the order of $0.8 \mathrm{Mm}^{-1}$ in spring and fall, respectively. This seasonal variation is in accordance with the seasonal variations of air mass origin with the highest occurrence during both spring and fall (Fig. 1). As depicted in Fig. 2, light absorption coefficient due to dust aerosols is observed during the whole year and represents $12.6 \pm 3.5 \%$ of the light absorption coefficient measured by the aethalometer on a yearly basis. It should be noted that the contribution of dust aerosols can account for more than half of the light absorption coefficient during short but intense dust events (Vrekoussis et al., 2005).

4.3 Comparison of BC measurements from different analytical protocols

Each dataset of EC measurements obtained using thermooptical (IMPROVE \& NIOSH), optical (AETHALO), and thermal (2-STEP) methods has been compared by linear regression analysis. In this analysis, both the regressioncalculated intercept and a slope with a zero intercept were calculated. The results of these various statistical analyses are given in Table 2. Precision $(\sigma)$ is defined following the equation reported in Lewtas et al. (2001). Periods of comparison are also reported in the Table, as all the methods were not available for the duration of the study. BC concentrations derived from aethalometer and reported in Table 2 were not corrected for dust absorption influence, since iron measure- ments were available only for the period (09/2001-04/2004).

As shown in this Table, comparison between the two thermo-optical methods is not satisfactory as $r^{2}$ and precision $(\sigma)$ were found to be 0.68 and $32.4 \%$, respectively. In addition, EC(NIOSH) concentrations were 15-20\% lower compared to EC(IMPROVE). This discrepancy might originate from the primary difference between the two thermo-optical protocols which is the allocation, at the NIOSH protocol, of carbon evolving at $870^{\circ}$ temperature in a helium atmosphere to OC rather than to EC (Chow et al., 2001). The most probable explanation of such whitening of the filter is that mineral oxides from dust aerosols - deposited on the filter - are supplying oxygen to neighboring carbon particles at this high temperature (Sciare et al., 2003b). Interestingly, the best correlation coefficient and precision for EC measurements are found between IMPROVE and AETHALO methods $\left(r^{2}=0.76, \sigma=18.3 \%\right)$, whereas the comparison between NIOSH and AETHALO methods is much less satisfactory $\left(r^{2}=0.65, \sigma=40.5 \%\right)$. This result confirms that the IMPROVE protocol relates in a more quantitative way the light absorbing properties of $\mathrm{BC}$ in our Mediterranean samples.

Comparison between IMPROVE and 2-STEP protocols showed the lowest correlation coefficient and precision $\left(r^{2}=0.46, \sigma=53.0 \%\right)$ with the EC levels from the 2-STEP method being $50 \%$ higher. This poor agreement is somehow expectable considering the major discrepancies that have been observed between these two methods during the MINOS campaign (Sciare et al., 2003b) and that have pointed out a more-pronounced sensivity of the EC(2-STEP) to combustion aerosols of fossil fuel origin (rather than of biomass burning origin).

4.4 Seasonal variation of black carbon: evidence of biomass burning

Agriculture waste burning and forest fires are likely to present an important temporal and interannual variability mainly related to weather conditions. This variability may shift the maximum of biomass burning for several weeks. To 


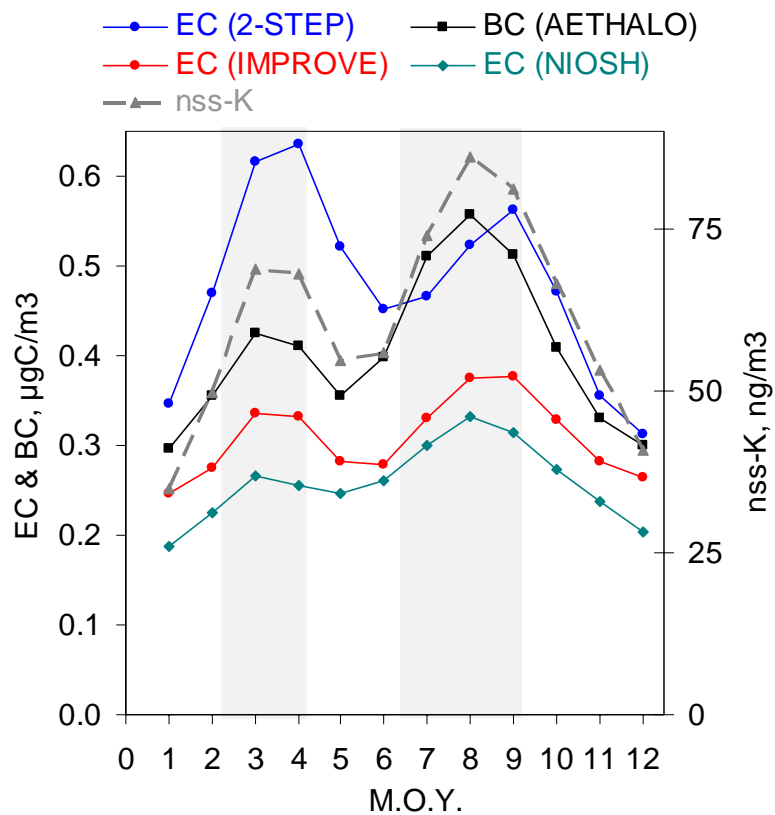

Fig. 3. Weighed seasonal variations of EC concentrations derived from two thermo-optical (IMPROVE and NIOSH) one optical (AETHALO) and one thermal (2-STEP) protocol. Non-seasalt potassium (nss-K) concentrations are those from the fine mode $(<1.5 \mu \mathrm{m})$. Grey bands refer to the two biomass burning periods (March/April) and (July-September).

take into account this variability a smoothing was applied to monthly mean concentrations following the equation:

$\overline{C_{i}}=\left(2 \times C_{i}+C_{i-1}+C_{i+1}\right) / 4$

where $\overline{C_{i}}$ stands for the smoothed monthly mean concentration of species $\mathrm{C}$ for the month i. $\mathrm{C}_{i-1}, \mathrm{C}_{i}$ and $\mathrm{C}_{i+1}$ are the monthly averages corresponding to month i minus one, month i and month i plus one, respectively.

Temporal variations of EC from the four different analytical methods described previously are given on a seasonal basis in Fig. 3, for the periods when these measurements are available (report to Table 1). Seasonal variations of nss-K are also given in this figure and show that two periods of the year are influenced by biomass burning, the early spring (March/April) and the summer months (July/September). Despite the discrepancies observed between the different EC measurements techniques, all measurements exhibit the two peaks of biomass burning periods although of different strengths.

Several observations were used in the following to better depict the origin of the two distinct periods of biomass burning (early spring and summer). First, hotspots/fire map products were obtained using data from the MODIS (Moderate Resolution Imaging Spectroradiometer) instrument and were downloaded from the web fire mapper built by the NASA funded Fire Information for Resource Management

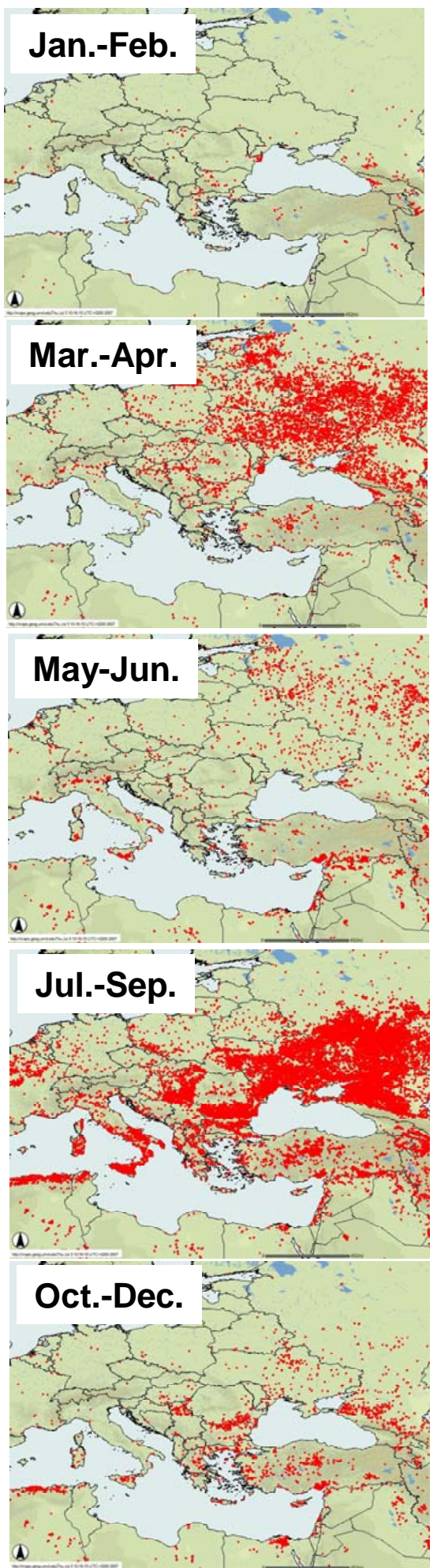

Fig. 4. Hotspot fire maps (FIRMS data) for the year 2004.

System (FIRMS, http://maps.geog.umd.edu/firms/). These hotspots/fire maps are given in Fig. 4 for different periods of the year 2004 and point out important fires in the 


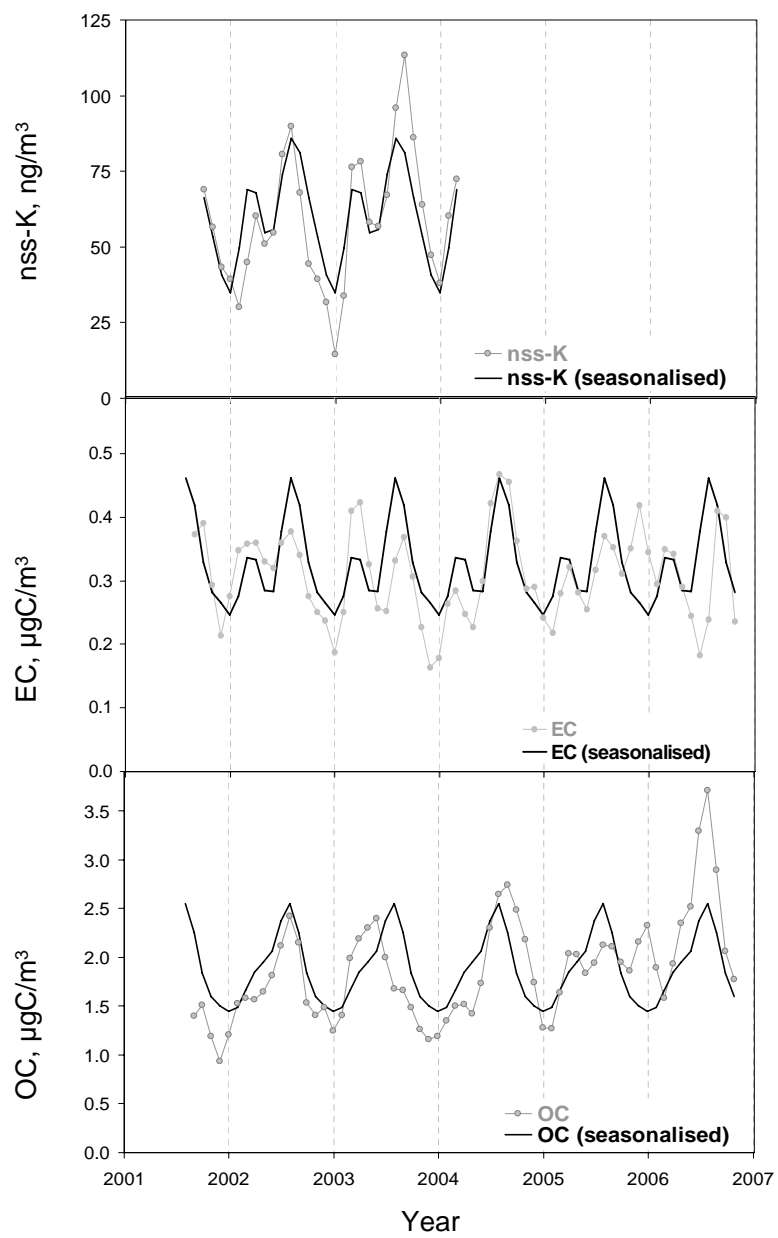

Fig. 5. Temporal variations of monthly mean EC and OC (IMPROVE) and nss-K concentrations in Crete Isl. Seasonalised variations of these compounds derived from Eq. (5) are reported in black lines.

surrounding regions of the Black Sea (Bulgaria, Romania, Moldavia, Ukraine, and Russia). Two periods with an increasing number of fire spots are clearly visible in this figure that correspond to the same periods reported previously (early spring and summer). Similar patterns can be obtained from the study of map products for other years (2001-2006) with, however, strong interannual variability in the number of hotspots/fires. These fires are likely to correspond to agricultural waste burning practices (post-harvesting for the summer months) and they are in agreement with the results reported by Van der Werf et al. (2006) for monthly fire emissions over Europe derived from satellite and model data. These biomass burning emissions from countries bordering the Black Sea are expected to have a significant impact over the E. Mediterranean since they are located in the northern wind sector of Crete Isl. which has the highest occurrence at the monitoring station (Fig. 1). Consequently, the stronger maximum of EC observed during summertime may originate from the higher occurrence of North sectors during this season. Alter- natively, the occurrence of fire spots shown in Fig. 4 is higher for the period July-September than for the period MarchApril and could also explain the intensity of our two EC and nss-K maxima in Fig. 3.

Multi-year Aerosol Optical Depth (AOD) measurements available in Moldova (i.e. within the region affected by the major fire spots reported in Fig. 4) and in Northern Greece (i.e. at half way between this region and our receptor site) were also used to assess the extent of biomass burning emissions over the E. Mediterranean. AOD, Angstrom exponent and Absorption measurements obtained at the Moldovan station (Aculinin et al., 2004 and AERONET almucantar retrieval products) exhibit very similar seasonal patterns with two concomitant peaks in March-April and July-September (data not show here). These results strongly suggest that the major aerosol source in Moldova at these two periods could be of combustion (biomass burning) origin. Similar results are obtained from AOD measurements in Northern Greece (Kazadzis et al., 2007) when air masses originating from the regions surrounding the Black Sea are investigated. All these optical measurements gathered with the seasonal EC variations in Crete contribute to the idea that biomass burning aerosols emitted in the regions surrounding the Black Sea are likely to significantly impact the aerosol absorbing properties in remote areas of E. Mediterranean located as far as 1500-2000 km downwind. Further evidence of these largescale biomass-burning aerosol emissions from Eastern $\mathrm{Eu}-$ rope was also found by Niemi et al. (2004, 2005), Arola et al. (2007), Saarikoski et al. (2007), and Stohl et al. (2007) over Northern Europe (Finland) and Arctic zone.

\subsection{Temporal variability of carbonaceous aerosols}

EC and OC concentrations obtained from the IMPROVE method are used in the following to investigate the temporal variability of carbonaceous aerosols as well as their different origins. This choice is motivated primarily by the fact that this IMPROVE method is less affected by analytical artifacts due to dust aerosols and that it shows the best agreement with absorption (AETHALO) measurements. Finally, this is the only time series of EC and OC that covers the entire sampling period. The monthly mean variations of EC(IMPROVE) and OC(IMPROVE) are reported in Fig. 5 for the 5-year period (09/2001-12/2006) together with 3.5-year record of nss-K. Seasonal variations of these compounds derived from equation (5) are also reported in the same figure to better highlight their important year-to-year variations. The important seasonal and interannual variations observed for both EC and OC can possibly be explained by the occurrence of North wind sectors, but also by the fact that biomass burning emissions, by nature, often last for short periods (typically less than a couple of days). These fugitive emissions are also known to have very important seasonal and interannual variations (van der Werf et al., 2006). 
Interestingly, the two peaks of biomass burning coincide with increase of nss- $\mathrm{K}^{+}$and EC and not with OC concentrations that exhibit one broad peak during the summer months. Other contributions than biomass burning should then account for this OC peak and could possibly originate from the formation of secondary organic aerosols (of biogenic/anthropogenic origin) as this season is associated with more intense photochemistry. Deconvolution of carbonaceous aerosols sources is tentatively performed in the next section to better characterize sources for organic aerosols other than biomass burning.

4.6 Deconvolution of the source origin of carbonaceous aerosols

Time duration of the fugitive emissions of biomass burning is expected to differ significantly at the sampling station from the more permanent and homogeneous anthropogenic fossil fuel emissions. Based on the time limited duration of these biomass burning episodes, and using the temporal resolution of filter sampling, each biomass burning event was isolated from the whole dataset using an arbitrary threshold nss-K concentration of $50 \mathrm{ng} / \mathrm{m}^{3}$, corresponding to a round average using the monthly mean nss-K concentrations for May and June (Fig. 3), two months which are poorly affected by biomass burning (Fig. 4). Each filter batch with nss-K concentrations higher than $50 \mathrm{ng} / \mathrm{m}^{3}$ was then defined as affected by biomass burning.

Data selection was then performed when nss- $\mathrm{K}$ is available (09/2001-04/2004) and 50\% of the whole initial dataset (i.e. 53 samples) has been consequently retained and used to calculate non-biomass burning concentrations of $\mathrm{EC}$ and $\mathrm{OC}$ (noted later as background $\mathrm{EC}^{*}$ and background $\mathrm{OC}^{*}$ ). Seasonal variations of $\mathrm{EC}^{*}$ and $\mathrm{OC}^{*}$ were then calculated using the smoothing of equation (5). Smoothed seasonal variations of EC and OC during the periods impacted by biomass burning origin (noted later as bb-EC and bb-OC) were then calculated on a monthly basis as:

$$
\begin{aligned}
& \mathrm{bb}-\mathrm{EC}=\mathrm{EC}(\text { IMPROVE })-\mathrm{EC} * \\
& \mathrm{bb}-\mathrm{OC}=\mathrm{OC}(\mathrm{IMROVE})-\mathrm{OC} *
\end{aligned}
$$

The hypothesis used for this deconvolution assumes that carbonaceous aerosol concentrations result from the addition of the two different and independent sources (background and biomass burning) and that this mixing will not further alter the composition/concentration of each source. Thus, it is assumed that OC/EC ratios for each source will remain unchanged with no extra formation of SOA due to the mixing of the two sources. The seasonal cycles of background (EC* and $\mathrm{OC}^{*}$ ) and biomass burning (bb-EC and bb-OC) carbonaceous aerosols and corresponding OC/EC ratios are presented in Fig. 6 with 1 standard deviation $(1 \sigma)$ and are discussed below.
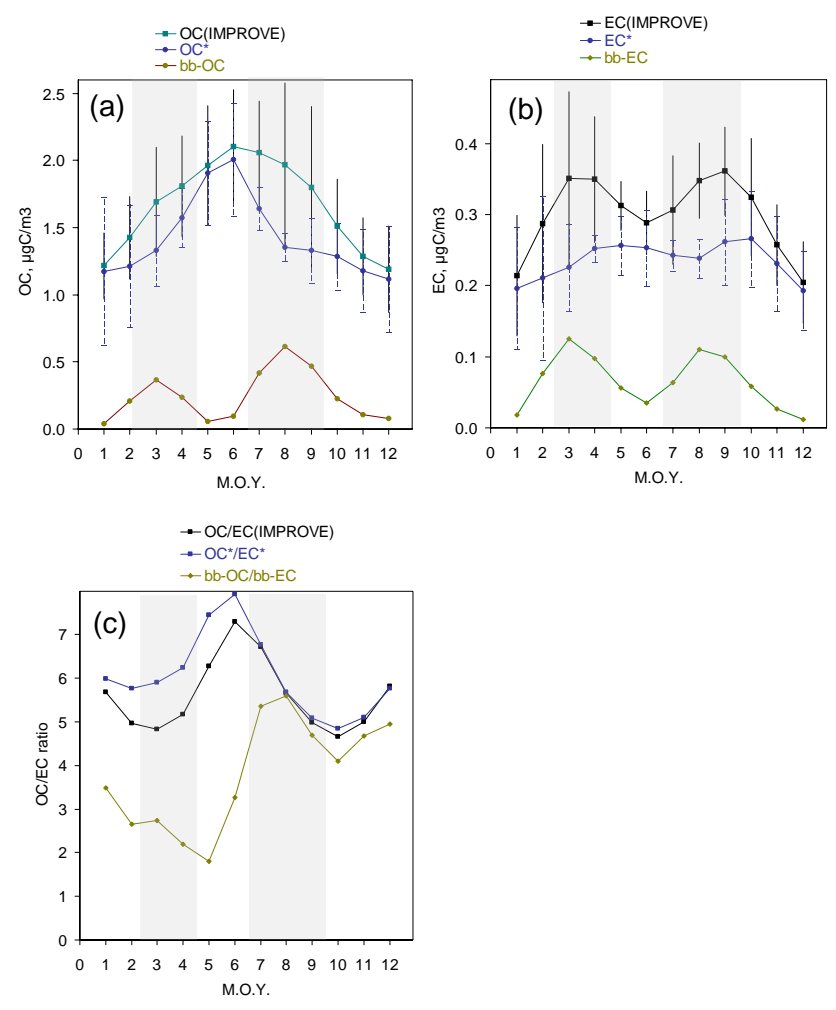

Fig. 6. Seasonal variations of EC, OC, and OC/EC derived from the IMPROVE temperature program, biomass burning (noted with bb-), and non-biomass burning (noted with*). Error bars stand for 1 standard deviation $(1 \sigma)$. Grey bands refer to the two biomass burning periods (March/April) and (July-September).

\subsubsection{Biomass burning carbonaceous aerosols}

The choice of a threshold value of $50 \mathrm{ng} / \mathrm{m}^{3}$ for $\mathrm{nss}-\mathrm{K}$ may be critical and can potentially alter the levels of deconvoluted bb-EC and bb-OC. Several sensitivity tests have been performed for that purpose, using different nss-K threshold values ranging from 40 to $60 \mathrm{ng} / \mathrm{m}^{3}$. These two limit values correspond to a restrained dataset (free of biomass burning events) that represents roughly $1 / 3$ and $2 / 3$ of the initial dataset, respectively. By varying the threshold value from 40 to $60 \mathrm{ng} / \mathrm{m}^{3}$, the levels of bb-EC and bb-OC were found to remain almost unchanged (compared to those obtained with a threshold value of $50 \mathrm{ng} / \mathrm{m}^{3}$ ) with month-to-month deviations of \pm 0.01 and $\pm 0.04 \mu \mathrm{gC} / \mathrm{m}^{3}$, respectively. Then, it appears that results on the seasonal variations of both bb-EC and bb-OC are not significantly altered by the choice of a threshold value of $50 \mathrm{ng} / \mathrm{m}^{3}$ for nss- $\mathrm{K}$ and give further confidence on the levels of bb-EC and bb-OC that are presented here.

As shown in Fig. 6, both bb-EC and bb-OC show a very similar seasonal cycle although they have been calculated independently. The observed two maxima (early spring and summer months) coincide exactly with our previous observations on the seasonality of biomass burning emissions. 


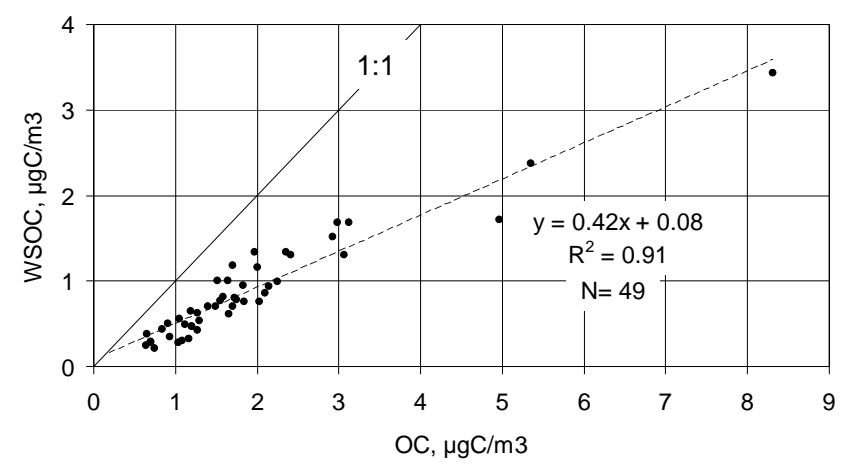

Fig. 7. OC versus WSOC for bulk aerosol samples collected during the period (10/2005-07/2006).

Although biomass burning is clearly identified as the only source responsible for the major seasonal variation of EC, its contribution on a monthly mean basis is quite variable, ranging from 6 to $40 \%$ ( $20 \pm 10 \%$ on average) with two maxima in March and August. Although biomass burning aerosols are characterized by high levels of OC relatively to EC, their contribution to the measured OC levels is slightly lower (compared to $\mathrm{BC}$ ) with monthly mean values ranging from 3 to $32 \%$ ( $14 \pm 10 \%$ on average) and a maximum for $\mathrm{Au}-$ gust. Noteworthy these calculations are averaged on a 3.5year period (09/2001-04/2004) and are expected to exhibit much more variability on a seasonal or interannual basis, depending on the source strength of biomass burning. The calculated bb-OC/bb-EC ratio is $3.8 \pm 1.3$ on a yearly average but shows an important seasonal variation with average values from 2.6 to 5.6 for winter and summer, respectively. Although this ratio is known to be highly variable depending on the different combustion stages (from flaming to smoldering), it is rather small compared to wood burning ratios commonly reported in the literature. Discrepancies between these two different ratios are even larger if we consider that the biomass burning aerosols collected in Crete have been highly processed during their transport, probably leading to an increase of the initial OC/EC ratio resulting from condensation of secondary organic aerosols (oxidation and condensation of biomass burning emitted VOCs). On the other hand, several studies have reported that open agricultural waste burning is likely to produce rather low OC/EC ratios ranging from 2.4 for wheat crop residuals (Hays et al., 2005) to 4.8 (Andreae and Merlet, 2001). Despite the different analytical protocols used for the determination of OC and EC, the OC/EC ratios reported in the literature are in the range of those reported here and fit with our findings on the agriculture origin of our biomass burning aerosols.

\subsubsection{Background carbonaceous aerosols (EC* and $\mathrm{OC}^{*}$ )}

Background carbonaceous aerosols can originate from various anthropogenic and natural sources. Fossil fuel is prob- ably a major source for $\mathrm{EC}^{*}$ over the E. Mediterranean in which coal burning should be a significant contributor as previously reported for $\mathrm{SO}_{2}$ in this region (Zerefos et al., 2000; Sciare et al., 2003a). As shown in Fig. 6, the seasonal variation of $\mathrm{EC}^{*}$ remains fairly constant with a yearly average of $0.24 \pm 0.04 \mu \mathrm{gC} / \mathrm{m}^{3}$, which is consistent with the general idea that fossil fuel emissions should be more or less the same during the year.

The seasonal variation of the $\mathrm{OC}^{*} / \mathrm{EC}^{*}$ ratio (Fig. 6) shows a sharp peak of 7.9 for the late spring (June) and a minimum of 4.8 for the month of October. The variations of this ratio are almost entirely related to $\mathrm{OC}^{*}$ as the levels of $\mathrm{EC}^{*}$ remain quite stable over the year. Contrary to $\mathrm{EC}^{*}$, the origin of $\mathrm{OC}^{*}$ is more uncertain and a significant secondary origin could account for the seasonal variation of $\mathrm{OC}^{*}$ which exhibits maximum values in late spring. Such seasonal pattern is not related in $\mathrm{EC}^{*}$ and thus should originate from other sources. Secondary aerosol formation driven by photochemistry could be proposed to explain the $\mathrm{OC}^{*}$ peak value in May-June. On the other hand, it hardly explains why $\mathrm{OC}^{*}$ is decreasing during summer, when photochemistry is at its maximum. Alternatively, a temperature driven mechanism leading to a volatilization of organic aerosols could be proposed as the summer months in Crete Isl. are characterized by high temperatures (typically higher than $35^{\circ}$ at mid-day).

\subsection{WSOC}

Assuming that a significant fraction of SOA originating from gas-to-particle formation can be related to WSOC (Weber et al., 2007; Kondo et al., 2007), a significant seasonal variation of the WSOC/OC ratio should be expected with a maximum during the summer months. This is not observed here since a quite stable sample-to-sample WSOC/OC ratio of $0.45 \pm 0.12$ was found for whole period when WSOC is available (10/2005-07/2006). This lack of seasonal pattern in the WSOC/OC ratio is further confirmed by the very good agreement found between WSOC and OC measurements $\left(r^{2}=0.91\right.$, Fig. 7). This result indicates that the $\mathrm{OC}^{*}$ increase (relative to $\mathrm{EC}^{*}$ ) observed in May-June (Fig. 6) is almost equally composed of water soluble and insoluble organic material. In other words, if this $\mathrm{OC}^{*}$ increase is due to SOA formation, it implies that this SOA comprise almost equally water insoluble and water soluble organic material, which is in contradiction with the previous studies suggesting that SOA is mainly composed of WSOC.

Similarly, biomass burning aerosols collected at our site seem to weakly affect the WSOC/OC ratio. All these results show the complexity of organic sources and ageing in the Mediterranean and point out the need for more time- and size-resolved measurements of $\mathrm{BC}, \mathrm{OC}$, and WSOC in order to further make conclusions on the mechanisms responsible for the enhancement of organic aerosols in late spring / early summer. 


\section{Conclusions and perspectives}

Long-term (5-year) measurements of carbonaceous (EC, OC) aerosols were reported here for the first time in the Mediterranean Basin (Crete Island). Light absorbing dust aerosols have shown to weakly contribute to the light scattering coefficient $\left(b_{a b s}\right)$ measurements performed by an aethalometer $(+12 \%$ on a yearly average). Comparison of soot carbon measurements performed with 4 different analytical protocols ( 2 thermo-optical, 1 optical, 1 thermal) have shown important discrepancies from one method to another. However, their seasonal trends were found to be quite similar showing two peaks (early spring and summer) corresponding to long-range transported biomass burning aerosols originating from apart to agriculture (post-harvest wheat residual) waste burning in the countries surrounding the Black Sea (i.e. at 1000-2000 km upwind of Crete). The contribution of biomass burning to the concentrations of EC and OC have been shown to be rather small on a yearly basis (20 and 14\%, respectively) but could be significant for some months (34 and 32\% of EC and OC, respectively, for the month of August) and are expected to present a strong seasonal/interannual variability. Noteworthy, these biomass burning aerosols are expected to have an even more important impact at the emission sources (mainly in Ukraine and surroundings countries) as observed from Aerosol Optical Depth measurements performed in Moldova.

Rabbinge and van Diepen (2000) suggested that the wheat yields in Ukraine have the potential to double, at least in the long run. As this country has the largest agriculture land area in Europe (FAO, 2003) and the highest European values for energy-crop potential (Ericsson \& Nilsson, 2006), agriculture (wheat crop residual) waste burning in this region is likely to represent a non-negligible source of combustion aerosols in the near future. Large emissions from biomass burning aerosols and corresponding influence on aerosol radiative forcing over the Ukraine and downwind regions (including the E. Mediterranean) is thus expected to remain significant for the coming years and should be taken into account in modeling studies of EC and OC over Europe. A quite similar statement can be provided for carbonaceous aerosols of fossil fuel origin. European countries bordering the Black Sea have particularly high $\mathrm{SO}_{2}$ emissions, contributing to more than one third of the total $\mathrm{SO}_{2}$ emissions reported over Europe in 2004 (Vestreng et al., 2007). Although $\mathrm{SO}_{2}$ emissions from these countries have drastically decreased in the nineties, they are expected to slightly increase $(+10 \%)$ at the end of 2010 . It is likely that levels of carbonaceous aerosols having the same origin as $\mathrm{SO}_{2}$ will remain high the coming years.

By removing the biomass burning influence, an important seasonal variation of organic aerosols was observed, with an increase by almost a factor of two for the spring months of May and June. Our preliminary measurements of WSOC have shown that the WSOC/OC ratio of $0.45 \pm 0.12$ remains unchanged, suggesting that water soluble and water insoluble organic matter do contribute almost equally to OC throughout the year.

All these results contribute to the general idea that E. Mediterranean has a complex mixture of highly processed carbonaceous aerosols of various origins. Further efforts will be required in the future to better characterize these carbonaceous aerosols as they may significantly alter the overall radiative forcing over the Mediterranean Sea and downwind regions.

Acknowledgements. This work has been funded by EGIDE (French Ministry of Foreign Affairs), EU-ACCENT program and partially by EU-ADIOS program, ECPL, CEA, and CNRS. The authors want to express their acknowledgement to the two anonymous reviewers for their suggestions and remarks and the ECPL team involved in the filter sampling and analysis.

Edited by: V.-M. Kerminen

\section{References}

Aculinin, A., Holben, B., Smirnov, A., and Eck, T., Measurements of aerosol optical properties at the Kishinev site, Moldova, Moldavian J. of Phys. Sci., 3, 2, 2004.

Andreae, M.O., and Merlet, P., Emission of trace gases and aerosols from biomass burning. Global Biogeochem. Cycles, 15, 955966, 2001.

Arola, A., Lindfors, A., Natunen, A., and Lehtinen, K. E. J., A case study on long-range transported aerosols of biomass burning: effects on aerosol optical properties and surface radiation levels, Atmos. Chem. Phys., 7, 4257-4266, 2007

Bardouki, H., Liakakou, H., Economou, C., Sciare, J., Smolik, J., Zdimal, V., Eleftheriadis, K., Lazaridis, M., Dye, C., and Mihalopoulos, N., Chemical composition of size-resolved of atmospheric aerosols in the Eastern Mediterranean during summer and winter, Atmos. Environ., 37, 195-203, 2003.

Barnaba, F., and Gobbi, G. P., Aerosol seasonal variability over the Mediterranean region and relative impact of maritime, continental and Saharan dust particles over the basin from MODIS data in the year 2001, Atmos. Chem. Phys., 4, 2367-2391, 2004, http://www.atmos-chem-phys.net/4/2367/2004/.

Birch, M.E., Cary, R.A., Elemental carbon-base method for monitoring occupational exposures to particulate diesel exhaust, Aerosol Sci. Technol., 25, 221-241, 1996.

Bonnet, S. and Guieu, C., Atmospheric forcing on the annual iron cycle in the western Mediterranean Sea: A 1-year survey, J. of Geophys. Res., 111, 2006.

Bryant, C., Eleftheriadis, K., Smolik, J., Zdimal, V., Mihalopoulos, N., and Colbeck, I., Optical properties of aerosols over the eastern Mediterranean, Atmos. Environ., 40, 6229-6244, 2006.

Cachier, H., Brémond, M.P., Buat-Ménard, P., Determination of atmospheric soot carbon with a simple thermal method. Tellus 41B, 379-390, 1989.

Chow, J.C., Watson, J.G., Pritchett, L.T., Pierson, W.R., Frazier, C.A., and Purcell, R.G., The DRI Thermal/Optical Reflectance Carbon Analysis System : Evaluation and Applications in U.S. Air Quality Studies, Atmos. Environ., 27A, 1185-1201, 1993. 
Chow, J.C., Watson, J.G., Crow, D., Lowenthal, D. H., and Merrifield, T., Comparison of IMPROVE and NIOSH carbon measurements, Aer. Sci. Technol., 34, 23-34, 2001.

Draxler, R.R., and Hess, G.D., An overview of the HYSPLIT_4 modelling system for trajectories, dispersion and deposition, Aust. Met. Mag. 47, 295-308, 1998.

Ericsson, K., and Nilsson, L.J., Assessment of the potential biomass supply in Europe using a resource-focused approach, Biomass and Bioenergy 30, 1-15, 2006.

FAO, FAOSTAT Agriculture Data, Food and Agricultural Organization, the Statistics Division, 2003.

Fialho, P., Hansen, A. D. A., et al. Absorption coefficients by aerosols in remote areas: a new approach to decouple dust and black carbon absorption coefficients using seven-wavelength Aethalometer data, J. Aerosol Sci., 36, 267-282, 2005.

Guieu, C., Bonnet, S., and Wagener, T., Loÿe-Pilot, M.D, Biomass burning as a source of dissolved iron to open ocean? Geophys. Res. Let., 32, L1960810.1029/2005GL022962, 2005.

Gerasopoulos, E., Kouvarakis, G., Vrekoussis, M., Donoussis, C., Mihalopoulos, N., and Kanakidou, M., Photochemical ozone production in the Eastern Mediterranean , Atmos. Environ., 40, 3057-3069, 2006.

Gerasopoulos, E., Koulouri, E., Kalivitis, N., Kouvarakis, G., Saarikoski, S., Mäkelä, T. Hillamo, R., Mihalopoulos, N., Sizesegregated mass distributions of aerosols over Eastern Mediterranean: seasonal variability and comparison with AERONET columnar size-distributions, Atmos. Chem. Phys., 7, 2551-2561, 2007 , http://www.atmos-chem-phys.net/7/2551/2007/.

Hansen, A.D.A., Rosen, H., and Novakov, T., Real-Time measurement of the absorption coefficient of aerosol particles, Appl. Opt., 21, 3060-3062, 1982.

Hays, M.D., Fine, P.M., Geron, C.D., Kleeman, M.J., and Gullett, B.K., Open burning of agricultural biomass: Physical and chemical properties of particle-phase emissions, Atmos. Environ., 39, 6747-6764, 2005.

Kazadzis, S., Bais, A., Amiridis, V., Balis, D., Meleti, C., Kouremeti, N., Zerefos, C. S., Rapsomanikis, S., Petrakakis, M., Kelesis, A., Tzoumaka, P., and Kelektsoglou, K., Nine years of UV aerosol optical depth measurements at Thessaloniki, Greece, Atmos. Chem. Phys., 7, 2091-2101, 2007, http://www.atmos-chem-phys.net/7/2091/2007/.

Kondo, Y., Miyazaki, Y., Takegawa, N., Miyakawa, T., Weber, R. J., Jimenez, J. L., Zhang, Q., and Worsnop, D. R., Oxygenated and water-soluble organic aerosols in Tokyo, J. Geophys. Res., 112, D01203, 2007.

Kouvarakis G., Tsigaridis K., Kanakidou M., and N. Mihalopoulos, Temporal variations of surface regional background ozone over Crete Island in the Southeast Mediterranean. J. Geophys. Res., 105, 4,399 - 4,407, 2000.

Lelieveld, J. H. Berresheim, S. Borrmann, P. J. Crutzen, F. J. Dentener, H. Fischer, J. Feichter, P. J. Flatau, J. Heland, R. Holzinger, R. Korrmann, M. G. Lawrence, Z. Levin, K. M. Markowicz, N. Mihalopoulos, A. Minikin, V. Ramanathan, M. de Reus, G. J. Roelofs, H. A. Scheeren, J. Sciare, H. Schlager, M. Schultz, P. Siegmund, B. Steil, E. G. Stephanou, P. Stier, M. Traub, C. Warneke, J. Williams, H. Ziereis, Global Air Pollution Crossroads over the Mediterranean, Science, 298, 794-799, 2002.

Lewtas, J., Pang, Y. B., et al., Comparison of sampling methods for semi-volatile organic carbon associated with PM2.5, Aerosol Sci. and Technol. 34, 9-22, 2001.

Markowicz, K.M., Flatau, P.J., Ramana, M.V., Crutzen, P.J., Ramanathan, V., Absorbing Mediterranean aerosols lead to a large reduction in the solar radiation at the surface, Geophys. Res. Lett., 10.1029/2002GL015767, 2002.

Meloni, D., di Sarra, A., et al., Aerosol optical properties at Lampedusa (Central Mediterranean). 2. Determination of single scattering albedo at two wavelengths for different aerosol types, Atmos. Chem. Phys., 6, 715-727, 2006, http://www.atmos-chem-phys.net/6/715/2006/.

NIOSH, Elemental Carbon (Diesel exhaust). In NIOSH Manual of Analytical Methods. National Institute of Occupational Safety and Health. Cincinnati, OH, 1996.

NIOSH Method 5040, In NIOSH Manual of Analytical Methods (NMAM), $4^{\text {th }}$ ed., $2^{\text {nd }}$ Supplement, ed. Cassinelli M.E., O'Connor P.F. [Supplement to DHHS (NIOSH) Publication No. 94-113], 1998.

Niemi, J., Tervahattu, H., Vehkamaki, H., Kulmala, M., Koskentalo, T., Sillanpaa, M., Rantamaki, M., Characterization and source identification of a fine particle episode in Finland, Atmos. Environ., 38, 5003-5012, 2004.

Niemi, J., Tervahattu, V., H., et al., Characterization of aerosol particle episodes in Finland caused by wildfires in Eastern Europe, Atmos. Chem. and Phys., 5, 2299-2310, 2005.

Rabbinge, R., and van Diepen, C.A., Changes in agriculture and land use in Europe, Euro. J. of Agron., 13, 85-99, 2000.

Saarikoski, S., Sillanpaa, M., et al., Chemical composition of aerosols during a major biomass burning episode over northern Europe in spring 2006: Experimental and modeling assessments, Atmos. Environ., 41, 3577-3589, 2007.

Sciare, J., Bardouki, H., Moulin, C., and Mihalopoulos, N., Aerosol sources and their contribution to the chemical composition of aerosols in the Eastern Mediterranean Sea during summertime, Atmos. Chem. Phys., 3, 291-302, 2003a, http://www.atmos-chem-phys.net/3/291/2003/.

Sciare, J., Cachier, H., Oikonomou, K., Ausset, P., Sarda-Estève, R., and Mihalopoulos, N., Characterization of Carbonaceous Aerosols during the MINOS campaign in Crete, July-August 2001: a multi-analytical approach, Atmos. Chem. Phys., 3, 17431757, 2003b, http://www.atmos-chem-phys.net/3/1743/2003/.

Sciare, J., Oikonomou, K., Cachier, H., Mihalopoulos, N., Andreae, M. O., Maenhaut, W., and Sarda-Estève, R., Aerosol mass closure and reconstruction of the light scattering coefficient over the Eastern Mediterranean Sea during the MINOS campaign, Atmos. Chem. Phys., 5, 2253-2265, 2005,

http://www.atmos-chem-phys.net/5/2253/2005/.

Sciare, J., Cachier, H., Sarda-Estève, R., Yu, T., Semi-volatile aerosols in Beijing (R.P. China): Characterization and contribution to various PM2.5, J. Geophys. Res., 112 (D18), D18202, 2007.

Stohl, A., Berg, T., Burkhart, J. F., Fjæraa, A. M., Forster, C., Herber, A., Hov, Ø., Lunder, C., McMillan, W. W., Oltmans, S., Shiobara, M., Simpson, D., Solberg, S., Stebel, K., Ström, J., Tørseth, K., Treffeisen, R., Virkkunen, K., Yttri, K. E.: Arctic smoke record high air pollution levels in the European Arctic due to agricultural fires in Eastern Europe, Atmos. Chem. Phys., 7, 511-534, 2007, 
http://www.atmos-chem-phys.net/7/511/2007/.

Van der Werf, G. R., Randerson, J. T., Giglio, L., Collatz, G. J., Kasibhatla, P. S., and Arellano, A. F. Jr., Interannual variability in global biomass burning emissions from 1997 to 2004, Atmos. Chem. Phys., 6, 3423-3441, 2006,

http://www.atmos-chem-phys.net/6/3423/2006/.

Vrekoussis, M., Liakakou, E., Koçak, M., Kubilay, N., Oikonomou, K., Sciare, J., and Mihalopoulos, N., Seasonal variability of optical properties of aerosols in the Eastern Mediterranean, Atmos. Environ., 39, 7083-7094, 2005.

Vestreng, V., Myhre, G., Fagerli, H., Reis, S., and Tarrason, L., Twenty-five years of continuous sulphur dioxide emission reduction in Europe, Atmos. Chem. Phys., 7, 3663-3681, 2007, http://www.atmos-chem-phys.net/7/3663/2007/.
Weber, R. J., Sullivan, A. P., et al., A study of secondary organic aerosol formation in the anthropogenic-influenced southeastern United States, J. of Geophys. Res., 112, 2007.

Weingartner, E., Saathoff, H., et al., Absorption of light by soot particles: determination of the absorption coefficient by means of aethalometers, J. of Aer. Sci., 34, 1445-1463, 2003.

Zerefos, C., Ganev, K., Kourtidis, K., Tzortsiou, M., Vasaras, A., and Syrakov, E., On the origin of $\mathrm{SO}_{2}$ above Northern Greece, Geophys. Res. Lett., 27, 365-368, 2000 